\title{
Brucellosis is not only responsible for monoarthritis but it is also associated with other osteoarticular complications
}

\author{
Miguel A. González-Gay • Carlos García-Porrúa
}

Received: 2 June 2012/Accepted: 5 December 2012/Published online: 14 December 2012

(C) Springer-Verlag Berlin Heidelberg 2012

To the Editor,

We have read the singular case of brucellar monoarthritis reported by Cerit et al. [1]. Although the literature review performed by the authors was of potential interest, further comments on this issue deserve to be raised. With respect to this, human brucellosis used to be common in the Lugo region of Northwestern Spain [2]. It was an occupational disease caused by Brucella abortus infection [2]. Fortunately, its incidence has declined dramatically since the past nineties due to an intense campaign performed by the local health authorities [2]. Now, human brucellosis in that region is certainly uncommon, and in the last two decades, only few cases of brucellosis with more subtle and protracted manifestations have been observed [3, 4].

Unlike most cases described in the review conducted by Cerit et al. [1], Brucella abortus was the specie responsible for the cases of monoarthritis in Northwestern Spain [2]. Cerit et al. [1] stated that peripheral arthritis especially monoarthritis is the predominant musculoskeletal manifestation of brucellosis. It is true for a series of brucellosis occurring in South-American and Middle-East countries $[1,5]$. However, it was not the case for the patients from Lugo [2] as in this region; sacroiliitis and spondylitis,

\section{A. González-Gay $(\bowtie)$}

Rheumatology Division, Hospital Universitario Marqués de Valdecilla, IFIMAV, c/Avenida de Valdecilla, s/n,

39008 Santander, Spain

e-mail: miguelaggay@hotmail.com

\section{García-Porrúa}

Rheumatology Division, Hospital Lucus Augusti,

c/San Cibrao s/n, 27003 Lugo, Spain

e-mail: Carlos.Garcia.Porrua@sergas.es mainly involving the lumbar spine, accounted for most cases of osteoarticular complications of brucellosis. Peripheral arthritis was only observed in 7 of the 44 cases diagnosed with osteoarticular manifestations in the setting of human brucellosis in the Lugo region of Northwestern Spain [2]. Of interest, positive blood cultures for Brucella spp. were found in the 3 cases with peripheral oligoarthritis and in 2 of the 4 cases of monoarthritis. Furthermore, a positive synovial culture for Brucella spp. was obtained in 3 of the 4 cases with monoarthritis [2]. Therefore, blood and synovial cultures are mandatory in patients in whom brucella infection is suspected.

Finally, an issue that still remains unanswered is whether differences in the pattern of distribution of brucella arthritis among different countries may be the result of differences in the brucella species.

\section{References}

1. Cerit ET, Aydın M, Azap A (2012) A case of brucellar monoarthritis and review of the literature. Rheumatol Int 32(5): $1465-1468$

2. González-Gay MA, García-Porrúa C, Ibañez D, García-País MJ (1999) Osteoarticular complications of brucellosis in an Atlantic area of Spain. J Rheumatol 26(1):141-145

3. González-Gay MA, Blanco R, García-Pais MJ, Alonso P, Rodríguez A, Coira A, Mayo J (1997) Polymicrobial prepatellar septic bursitis caused by Brucella abortus and Streptococcus agalactiae. J Clin Rheumatol 3(2):120

4. García-Porrúa C, González-Gay MA, Vázquez-Caruncho M (1999) Magnetic resonance imaging in the early diagnosis of brucellar sacroiliitis. J Rheumatol 26(6):1422-1424

5. Zaks N, Sukenik S, Alkan M, Flusser D, Neumann L, Buskila D (1995) Musculoskeletal manifestations of brucellosis: a study of 90 cases in Israel. Semin Arthritis Rheum 25(2):97-102 